\title{
Development of Lemon fruit flavored Tasty Saline functional powder drinks
}

\author{
Bellal Hossain \\ Nutrition and Food Engineering department, Faculty of Allied Health Sciences, Daffodil International University, 102, Shukrabad, \\ Mirpur Road, Dhanmondi, Dhaka-1207, Bangladesh
}

\section{Email address:}

drbellal@daffodilvarsity.edu.bd

\section{To cite this article:}

Bellal Hossain. Development of Lemon Fruit Flavored Tasty Saline Functional Powder Drinks. Journal of Food and Nutrition Sciences. Vol. 2, No. 4, 2014, pp. 173-178. doi: 10.11648/j.jfns.20140204.22

\begin{abstract}
Nowadays, agglomerated citrus fruit flavored Tasty Saline functional powder drink represents a very appealing functional beverage for adult customers. It is produced by mixing basic ingredients (refined sucrose, refined common salt, encapsulated lemon flavor, dextrose anhydrous and potassium chloride) which were followed by agglomeration. Agglomeration is necessary, because non-agglomerated refined sucrose exhibit very poor flow and reconstitution properties. This research showed the influence of process conditions and composition of the different powder mixtures on the physical properties of the agglomerated final product. Agglomeration was conducted using batch fluid bed agglomerator at a constant air temperature $\left(60^{\circ} \mathrm{C}\right)$, with a constant addition of citric acid with acid regulators with varying duration of the process and varying amount of added water. Bulk density and particle size were conducted prior to and post agglomeration, while agglomerate hardness was estimated by conducting a compression test with a $30 \mathrm{~mm}$ probe on Texture Analyzer. Percentage of added water had a significant effect on bulk density and the duration of the agglomeration process. This effect was more significant with mixtures made with salt. As for mixtures with $0.45 \%$ to $0.55 \%$ encapsulated flavor, a significant influence of water addition on agglomerate median diameter was found. Agglomeration time and the percentage of added water showed dependence towards the composition of the mixture. This research showed that, in order to agglomerate powder mixtures successfully, parameters such as mixture composition, particle size, percentage of added water and acidulates, drying temperature, process duration and ambient conditions should be well coordinated and controlled to get agglomerates with optimal quality.
\end{abstract}

Keywords: Tasty Saline, Agglomeration, Rehydration, Bulk Density, Sensory Evaluation

\section{Introduction}

Citrus fruit flavored tasty Saline is to be considered as instant functional powder drinks that are specially formulated to help rehydrate during or after physical activity of peoples at different age level. The product usually rich in carbohydrates i.e., the most efficient source of energy. As well as, carbohydrates are important sources to control energy level after exercise and activity performance. Fruity tasty Saline usually contain sweetening agents, citrus fruit origin encapsulated flavor and salts as sodium chloride blended with potassium chloride .

Maximum fruity Saline powder drinks are moderately isotonic functional drinks, containing 4 - 5 heaped teaspoons of sugar per five ounce (13 and 19 grams per $250 \mathrm{ml})$ serving size. Sodium Chloride improves sensory properties of food products during intake of consumer's in the society. There are many reasons for adding salt into foods. During intake, taste receptor cells in taste bud of human physiological system are innervated by branches of the seventh, ninth, and tenth cranial nerves that synapse first in the brainstem prior to sending messages to other parts of the brain ((Bachmanov, et al., 2007) for evaluation of sensory characteristics.

Salt influences palatability of food items and emphasized other sensory systems of chemical parameters that contribute to overall flavor perception for product acceptances (Koza et al., 2005). Certain volatile compounds detected by smell receptors are often judged as "sweet" and contribute to judgments of any product's overall taste of sweetness and also acceptability (Schifferstein \& Verlegh, 1996) and analogous phenomenon may also occur for saltiness ( Manabe et al., 
2009). In a study, imaging the human brain (e.g., using functional magnetic resonance imaging) have shown that flavor information from these separate sensory systems comes together from several parts of the brain, most prominently in the orbitofrontal cortex (Rolls et al., 2010). The addition of certain ingredients with high flavor impact into the manufacturing process may assist to reducing the need for added salt. Fresh herbs with spices, citrus fruits, mustards, and vinegars that impart distinctive flavoring taste of products instead of added salt in the diet (MacGregor and de Wardener, 1998; Ram, 2008). In words, with a variety of foods (soups, rice, eggs, and potato chips), salt was found to improve the perception of product thickness, enhance sweetness, mask metallic or chemical off-notes, and round out overall flavor while improving flavor intensity (Gillette, 1985) . Influence on water activity is another proposed reason that salt may potentiate flavor in foods. Use of salt in food products causes the decrees of water activity, which can lead to an effective increase in the concentration of flavors and improve the volatility of flavor components (Delahunty and Piggott, 1995; Hutton, 2002). Higher volatility of flavor components may improve the aroma of food and contributes to product acceptances. A Clinical study in a populations observed that sodium depletion enhanced the salt liking permanently (Beauchamp, 1987 \& Leshem, 2009). Changing the crystal structure of salt may also produce the same salt taste from reduced amounts of salt in the product (Beeren, 2009). The hypothesized specificity of the salt taste mechanism makes the existence of a salt taste substitute unlikely, but it differs in principle from a sweet taste, where the taste bud receptor cell mechanisms are more easily mimicked by other molecules; as a consequence, there are many alternative sweeteners (Beauchamp and Stein, 2008). Potassium chloride has been proposed as a salt substitute either alone or in combination with table salt in food products to control bitter taste of potassium chloride (Beauchamp and Stein, 2008).

Researcher showed that the natural thirst mechanism makes individuals only approximately half of the amount of fluid they have lost ( Coyle, E. F. 2004 ) during their physical activity. It is found that the thirst mechanism does not initiate their drive to drink until $2 \%$ dehydration of body fluid level, of which a target point for positive performance (Sawka, M.N., Montain, S.J. 2000 ).

Human body having remarkable ability to maintain sodium and water balance throughout deflective conditions for ensuring survival. Ultra endurance events challenge the survival mechanism. In hot, humid conditions a large amount of sweat is lost, which can disturb sodium and water balance in human body. Adequate hydration and sodium intake of long races athletes meet up the requirements either from sports drinks or food supplements to become more active. The exact mechanisms are not fully understood into the complex physiologic pathways of sodium and water balance. The simplest lost sweat (salt and water) is replaced by ingested water (no salt). This dilutes the sodium in the bloodstream, might be causes hyponatremia . Longer hard work causes the risk of hyponatremia due to sweat lost. During physical activity in the heating condition, electrolytic salt decreases in sweat per hour which usually replaced by food and fluids. Human body can tolerate a degree of imbalance for a short period of time, but it may decompensate if this continues for too long. Sweat contains 2.25 to 3.40 grams of salt per liter, and the rate of perspiration in a long activity loses average one liter per hour. So, for 12 hour work, one could lose approximately 27 to 41 grams of salt. The spectrum of symptoms can range from mild to severe and can include nausea, muscle cramps, disorientation, slurred speech, confusion, and inappropriate behavior due to loss of micro nutrients with fluid through Sweating during hard activity. As it progresses, victims may experience seizures or coma, and death can occur. Severe hyponatremia is a true medical emergency. Minor symptoms, such as nausea and mild muscle cramps, can be treated by eating salty foods and hydrating with sodium containing functional drinks. At present different types of commercial sodium enriched functional drinks i.e., Gatorade contains $110 \mathrm{mg}$ sodium; and Power tech $95 \mathrm{mg}$ are available in the market.

The objectives of this study were to develop newly formulated lemon fruit flavored tasty Saline as ready to use functional powder drinks for electrolytic balance after dehydration due to fluid loss.

\section{Materials and Methods}

\subsection{Materials}

Salt is made up of sodium and chloride. The FDA labels list only the sodium content. This is because there are usually other sodium containing salts (eg. sodium citrate) in these products. To avoid confusion, the easiest way to ensure that have enough sodium intakes is to get used to reading the FDA labels. One gm (1000mg) of sodium into food supplements would need to drink more than 2.18 liters of functional drinks certainly impractical every hour. In 1 gram of sodium from table salt need to ingest 2.5 grams (1 gm from sodium, $1.5 \mathrm{gm}$ from chloride). Refined sugar, and anhydrous dextrose were collected from local sugar refining industry; potassium chloride, Citric acid, Sodium Citrate and encapsulated lemon flavor from Symrise ,Malaysia.

\subsection{Methods}

\subsubsection{Machine Design}

Fluid bed processing equipments for the food industries require high sanitary standards, self-emptying capability, and automatic cleaning systems. Often products are required in agglomerate or granular form to achieve good instant properties and so fluid bed dryers may be combined with spray drying, agglomeration, or granulation systems (Mukherjee S, Bhattacharya S,2006). Featuring atmospheric air in a once-through system where water is to be removed. Normally a push-pull system is used to balance the pressure 
to be slightly negative in the free board of the fluid bed. Depending upon the product and available heat source, direct or indirect heating may be applied. The exhaust air is cleaned by e.g. bag filter, cyclone with or without wet scrubber. In fluid bed cooling, cold gas (usually ambient or conditioned air) is used. Conditioning of the gas may be required to achieve sufficient product cooling in an economically sized plant and to prevent pick up of volatiles (usually moisture). Heat may also be removed by cooling surfaces immersed in the fluidized layer. Agglomeration and granulation may be performed in a number of ways depending upon the feed to be processed for the achieved of product properties . Fluid bed coating of powders, granules, or tablets involves the spraying of a liquid on the fluidized powder under strictly controlled conditions. Fluid bed drying is suited for powders, granules, agglomerates, and pellets with an average particle size normally between 50 and 5,000 microns. Very fine, light powders or highly elongated particles may require vibration for successful fluid bed drying.

In this study design, upstream and downstream batch fluid processing was considered. The design having a system running with fluid bed processor in a batch mode simplifies material handling. The processing steps were dry mixing followed by drying for granulation by post drying and cooling to operate a continuous processor having multiple processing zones.

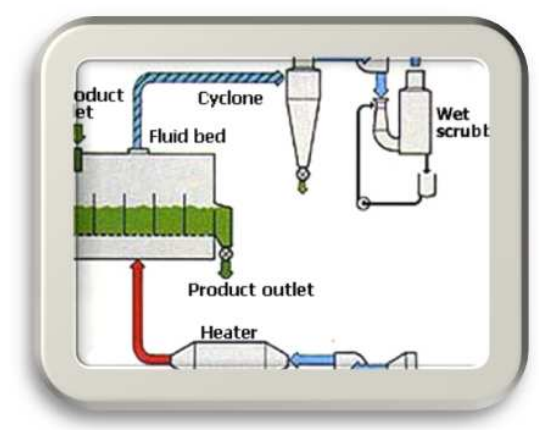

Figure 1. Schematic diagram of Open System Fluid Bed System

For the products pose a dust explosion risk, open cycle systems feature pressure shock resistant components, selfinertizing layouts has considered.

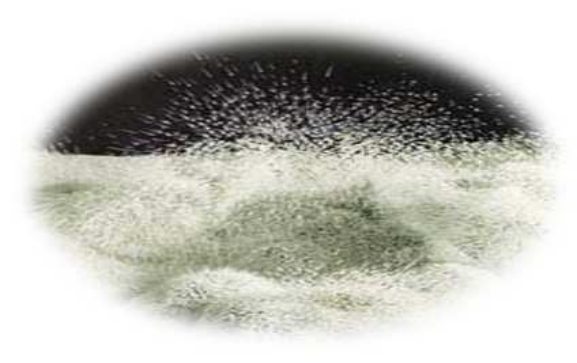

Figure 2. Picture of Product

Particle fluidization gives easy material transport, higher rate of heat exchange at high thermal efficiency preventing overheating of individual particles.
The properties of a given product are determined from drying rate data, i.e. how volatile content changes with time in a batch fluid bed operating under controlled conditions. Other important properties were fluidization gas velocity, fluidization point (i.e. the volatile content below which fluidization without mechanical agitation or vibration was possible), equilibrium volatile content, and heat transfer coefficient for immersed heating surfaces. These and other data are applied in a computational model of fluid bed processing, thus enabling dimensioning of industrial drying systems.

\subsubsection{Deflagration Resistant Designs}

Rapid combustion was always a concern when handling powders, especially dispersed in a fluidizing air stream for its batch processors with grounding systems to minimize charge build up. The ground systems were interlocked with the control system.

Combustion was still a 10 bar (150 psig) designs to contain deflagrations, eliminating the need for explosion relief ducts. This design reduces the required size of explosion relief ducts.

The unit was equipped with deflagration shut off valves to isolate the inlet air preparation and exhaust duct from the pressure build up.

\subsubsection{Fill and Discharge Options}

Two methods were available for filling and emptying the processor. With a removable bowl system the processor bowl was removed from the processor and taken to another location for filling and emptying. A wheeled trolley was supplied for moving the bowl and an automated system was included to lock the bowl into the processor. With this option the processor bowl becomes part of the material handling system.

Gravity feed and pneumatic discharge systems were inclined. With this approach the feed was poured into the processor via a fill port on the side. Feed was discharged pneumatically using the main processor fan to supply the motive air and Screw Feeders .

\subsubsection{The Product}

Because Tasty saline drink powders usually consist of about $36.5 \%$ sugar and $46.65 \%$ dextrose anhydrous powder, the ratio served as a basis for the preparation of experimental tasty saline drink mixtures. The salt to sugar ratio selected for experimental blends were adjusted according to the relative sweetness of selected sugar and Dextrose.

Table 1. Formulation of Tasty Saline

\begin{tabular}{lll}
\hline SI No & Ingredients & Amount in unit \\
\hline 1 & Refined Sugar crystal & $36.50 \%$ \\
2 & Dextrose anhydrous powder & $46.65 \%$ \\
3 & Sodium Chloride & $5.02 \%$ \\
4 & Sodium Citrate & $2.40 \%$ \\
5 & Citric Acid & $5.02 \%$ \\
6 & Potassium Chloride & $4.3 \%$ \\
7 & Encapsulated Lemon flavor & $0.35 \%$ \\
\hline
\end{tabular}




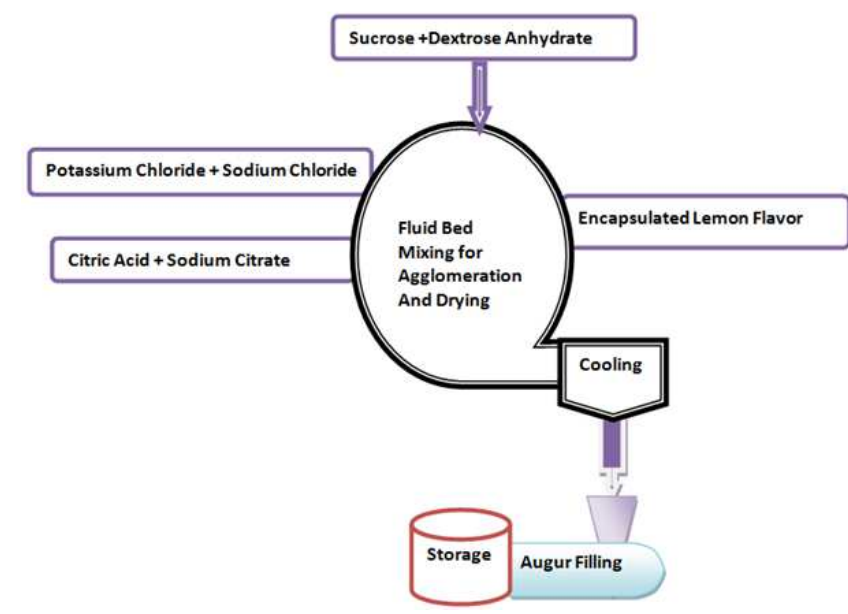

Figure 3. Flowchart diagram of Fruit flavored tasty functional drinks powder

\subsubsection{Quality Control Parameters}

\subsubsection{Moisture Content}

Moisture content of the used sweeteners and experimental mixtures was determined according to the official AOAC method by drying the samples at $105^{\circ} \mathrm{C}$ to constant weight. The moisture content was determined by weight difference and expressed as a percentage of the initial sample weight.

\subsubsection{Particle Size}

The particle size of product was investigated because of its effect on cohesion, bulk density, dispersibility, and solubility of the formulated blends. The particle size of the used sugars was characterized using conventional sieving analysis. Sieves were manufactured by Fritsch, Germany. The powders were sieved for 15 min using an Analysette 3 PRO laboratory shaker manufactured by Fritsch with a 2.5 $\mathrm{mm}$ vibration amplitude and a 3 second interval time. The results of the sieving analysis were tabulated to show the particle size range of sugar samples.

\subsubsection{Bulk Density}

Bulk density of the samples was determined following a modified method(Murakami, H.; 2001) . Sample was poured into a $100 \mathrm{ml}$ measuring cylinder, and the masses of the empty and filled measuring cylinders and the volume occupied by the sample were recorded. Bulk density was determined by dividing the net weight of the sample with the volume occupied by the sample in the cylinder.Bulk density was calculated as an average value of 10 measurements.

\subsubsection{Dispersibility, Solubility, and Wet Ability}

Dispersibility was determined following a modified method of (Shittu, T. A.; Lawal, M. O. 2007). Five grams of each sample was dissolved in $50 \mathrm{~mL}$ of distilled water at $27{ }^{0} \mathrm{C}$. The mixture was stirred manually for $1 \mathrm{~min}$ and allowed to rest for $24 \mathrm{~h}$ before the supernatant was decanted. The density of the supernatant was determined by filling $25 \mathrm{ml}$ of the supernatant in a density bottle. The weight of the dispersed sample was calculated as twice the difference between the mass of the supernatant and an equal volume of distilled water. Solubility was determined as described by (Takashi and Seibi, 1988), with some modifications. An amount of $5 \mathrm{~g}$ of each sample was suspended in $50 \mathrm{ml}$ of distilled water at $30^{\circ} \mathrm{C}$. The suspension was stirred occasionally for $30 \mathrm{~min}$ and centrifuged at $9500 \mathrm{rpm}$ for $10 \mathrm{~min}$. The supernatant was drained into an evaporating dish and dried at $105^{\circ} \mathrm{C}$ to constant weight. The weight of the solids recovered after drying was used to calculate the water solubility. Wettability was determined as described by Schubert, being considered as the time (se) required for all of the powder to become wetted and penetrate the surface of the distilled water at $27{ }^{\circ} \mathrm{C}$. Analyses were done in triplicate.

Table 2. Physicochemical Characteristics of Tasty Saline Powder drinks

\begin{tabular}{ll}
\hline Physical Characteristics & Results \\
\hline Bulk density, tapped 1250X & $0.80 \mathrm{~g} / \mathrm{cm}^{3}$ \\
WPNI & $3 \mathrm{mg} / \mathrm{g}$ \\
Insolubility index & $>0.1 \mathrm{ml}$ \\
Bulk density & $1.35 \mathrm{~g} / \mathrm{cm}^{3}$ \\
Mean particle size & $50 \mu \mathrm{m}$ \\
Amount above $100 \mu \mathrm{m}$ & $\max .25 \%$ \\
\hline
\end{tabular}

\subsubsection{Sensory Evaluation}

Consumer preference tests were conducted for the products Lemon flavored tasty saline powder drinks. During analysis, a group of 30 trained panelists were asked to evaluate the sample. The sample was served in $50 \mathrm{ml}$ aliquots in $100 \mathrm{ml}$ glasses at room temperature $\left(25^{\circ} \mathrm{C}\right)$ in a systematically varied order using hedonic rating score design. The panelists were asked to rank the samples from extremely liking to disliking. ANOVA, and multiple comparisons, analysis were conducted on the data. A correlation was drawn between the acceptability of the sample and other attributes of the 30 panelist. The data from the panelist hedonic test were subjected to ANOVA to determine the least significant difference (LSD) between means at the $5 \%$ levels. The five-point hedonic scale was used in the assessment of the consumers' degree of liking of the attributes (Lawless \& Heymann, 1998). The scale dependent on the size of the panel and panelists were asked to rate their five categories: $5=$ Like extremely, $4=$ Like moderately, 3 = Neither like nor dislike, 2 = Dislike slightly, 1 = Dislike extremely (Lawless \& Heymann, 1998). The samples were freshly prepared approximately $0.5 \mathrm{~h}$ before the panel testing. The samples were served in a complete randomized order. Water was provided for the cleansing of the glassware. The hedonic scale allowed for aroma, sweetness, saltiness, mouth feel and acceptance testing.

\subsubsection{Statistical Analysis}

A randomized complete design was used with five treatments for the sensory analyses of newly developed samples. The panelists, sensory data were subjected to test analyses of variance (ANOVA) using SAS ${ }^{\circledR}$ software (Version 9; SAS ${ }^{\circledR}$ Institute Inc, Cary, USA). ANOVA was conducted on the sensory data to test for reliability 
(Judge*Replication interaction) and internal consistency (Judge*Level interaction). Single, nonconforming judges were identified and removed using the SAS ${ }^{\circledR}$ diagram. Student's t-tests for the least significant difference (LSD) were calculated for the consumer, sensory data at the $5 \%$ significance level. These least significant differences were used to compare treatment means.

\section{Results and Discussions}

Proximate results of the citrus fruit flavored functional tasty Saline functional powder drinks are shown in table 3.

Table 3. Proximate values of tasty saline

\begin{tabular}{lll}
\hline Parameters & Amount & Methods of Analysis \\
\hline Moisture & $2.70 \%$ & AOAC, weigh metric \\
Sugar Content & $79.80 \%$ & AOAC, \\
Acidity & $0.20 \%$ & AOAC, Titrimetric \\
Salt & $16.00 \%$ & AOAC, \\
\hline
\end{tabular}

As expected, the simple sugars as a percentage of total carbohydrate was approximately $79.80 \%$ of the Sample with $16 \%$ total salt including sodium and potassium chloride.

Table 4. Mean Score of sensory attributes

\begin{tabular}{lll}
\hline Attributes & Mean \pm SD & t value, $\mathbf{p}<\mathbf{0 . 0 5}$ \\
\hline Aroma & $1.6667 \pm 0.7581$ & 2.05 \\
Sweetness & $1.6667 \pm 0.8023$ & 2.05 \\
Saltiness & $1.6774 \pm 0.8321$ & 2.04 \\
Mouth feel & $2.2333 \pm 0.2333$ & 2.05 \\
Acceptability & $2.0000 \pm 0.9469$ & 2.05 \\
\hline
\end{tabular}

The mean scores of sensory liking for saltiness, sweetness, aroma, mouth feel and acceptability, and willingness to give the product as functional drinks on the 5 -point scale ranged from 1 to 5 selected for the sensory study. In the table 4 , the mean and \pm SD are aroma (1.6667 $\pm 0.7581, \mathrm{p}<0.05)$, Sweetness (1.6667 $\pm 0.8023, \mathrm{p}<0.05)$, Saltiness $(1.6774 \pm 0.8321, \mathrm{p}<0.05)$,Mouth feel $(2.2333$ $\pm 0.2333, \quad \mathrm{p}<0.05)$ and acceptability $(2.0000 \pm 0.9469$, $\mathrm{p}<0.05$ ) respectively.

Table 5. Analysis of Variances (ANOVA) among the sensory attributes

\begin{tabular}{llllll}
\hline Sources & $\begin{array}{l}\text { Sum of } \\
\text { Square }\end{array}$ & $\mathbf{d}_{\mathbf{f}}$ & $\begin{array}{l}\text { Mean } \\
\text { Square }\end{array}$ & Probability & F- ratio \\
\hline Between group & 3.9310 & 4 & 0.9928 & 0.2 & 1.2651 \\
Within group & 108.7587 & 140 & 0.7768 & & \\
Total & 112.6897 & 144 & & & \\
\hline
\end{tabular}

Analysis of Variance gives the results regarding rejection of the null hypothesis (Table 5 ). Therefore, ANOVA was chosen, as recommended by Montgomery (Christophe Lalanne, 205 ), to compare the means of the scores of the sensory attributes evaluated by the participants. The order of liking the product was saltiness, sweetness, aroma, mouth feel and acceptability, and willingness to use the sample in their panelists as functional powder drinks (Fig. 3). All sensory attributes of the tasty saline were judged to be acceptable on all of the indicators . F ratio shows a significant result $(\mathrm{p}<0.2)$ of hedonic rating score of sensory attributes.

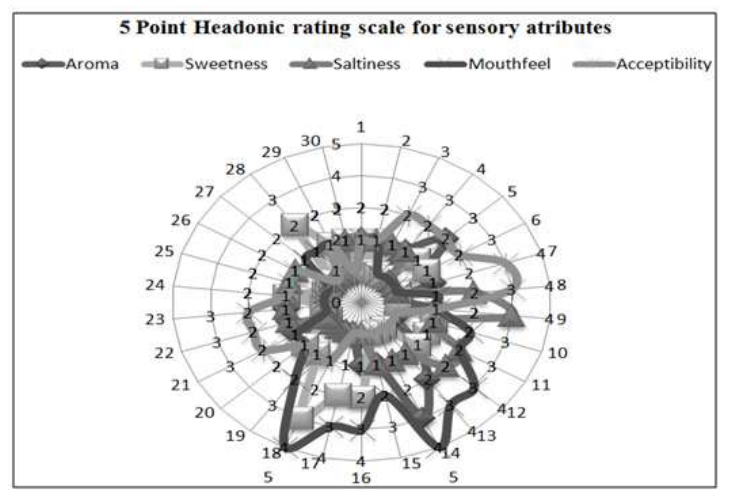

Figure 4. Diagrammatic presentation of product liking for sensory attributes and choice to give the sample as functional drinks to consumers by 30 participants

Sensory attribute with $P<0.05$ indicates that significant difference among the attributes value in parenthesis is asymptotic significance from Kruskal-Wallis test. A 5point hedonic scale was used for all attributes (Extremely like-1,M Like-2, Slightly like-3, like-4 and dislike-5). For analyzing the perceptions for Sweetness 5, Saltiness 4.3, Aroma 4.6, Mouth feel 3.6 and Acceptability 3.6 out of total 5 in the figure 3 . Chi square Test for extremely liking is 0.6637 at $95 \% C I, \mathrm{P}=1.00$ and moderately liking is 0.6561 at $95 \% C I, \mathrm{P}=1.00$ for tasty saline indicating significant results of sensory attributes . Multiple regression analysis of sensory attributes is calculated using the equation :-

$\mathrm{Y}=1.44395+-0.32069 \mathrm{X} 1+-$

$0.16228 \mathrm{X} 0.30085 \mathrm{X} 2+0.22503 \mathrm{X} 2$

and the result is shown in table 5 .

Table 6. Multiple regression coefficient of the sensory attributes

\begin{tabular}{llllll}
\hline Liking & Regression coefficient & Standard Deviation & T value & Probability & 95\% CI \\
\hline Extremely liking of the sample & -0.32069 & 0.19571 & -1.606 & 0.11 \\
Moderately liking of the products & -0.16229 & 0.19622 & -0.82704 & 0.416 & 0.72463 \\
\hline
\end{tabular}

Acceptability rating was $3.6,(\mathrm{P}<0.05)$. Consequently, appearance rating showed a high inverse correlation (0.598 ) with aroma. Panelists rated the sample higher with increase in sweet- citrus fruit aroma and saltiness. However, panelist ratings the samples above the mid-point and therefore were acceptable and significant The ratings for mouth feel ranged 3.6, $(\mathrm{P}<0.05)$. The sample was rated higher for mouth feel and was rated least $(\mathrm{P}<0.05)$. Mouth feel rating showed an inverse correlation with lemon aroma content $(-0.246)$, indicating that these parameters affected the mouth feel attribute negatively. An inverse correlation value for sweetness $(-0.365)$ and positive values for salt 
content (0.019) were observed with panelist taste rating (Table 5 ). However, the ratings of the tasty saline were above the mid-point for acceptability. Aroma ratings was 4.6 and the panelist ratings for aroma were significant $(\mathrm{P}<0.05)$. This may be attributed to the aroma imparted by the compositional interactions of the samples. Regression coefficient showed a negative correlation value for extremely liking of the sample $(-0.32069)$ and moderately liking $(-0.16229)$ and the $\mathrm{R}^{2}=0.18646(\mathrm{p}<0.05)$ indicates significant sensory attributes of the tasty saline.

\section{Conclusions}

For optimal physical working performance, especially in hot environments, it is important to drink regularly. Fruit saline powder drinks that contain sodium may help to rehydrate faster than those without, and added carbohydrates may ward off muscle fatigue. However, sodium intakes should generally be reduced in most diets to avoid adverse health effects.

\section{Recommendations}

Some experts recommend drinking less water to rebalance sodium and water intake. However, given the risk of dehydration and heat injury, this is not a practical recommendation. To reiterate, all of the hyponatremic persons in Bangladesh were also dehydrated. Other researchers recommend increasing salt intake, which seems to be more prudent. By ingesting more sodium, hydration with water is balanced without dilution of blood -sodium .

\section{References}

[1] Bachmanov AA, Beauchamp GK. Taste receptor genes. Annual Review of Nutrition. 2007; 27:389-414.

[2] Beauchamp GK, Bertino M, Engelman K. Failure to compensate decreased dietary sodium with increased table salt usage. Journal of the American Medical Association. 1987;258(22):3275-3278.

[3] [3] .Beeren C. Technological innovations for reducing sodium in foods. Presented at the Institute of Medicine Committee on Strategies to Reduce Sodium Intake's Public Information- Beeren C. Technological innovations for reducing sodium in foods. Presented at the Institute of Medicine Committee on Strategies to Reduce Sodium Intake's Public Information-Gathering Workshop; March30; Washington, DC. 2009.

[4] Coyle, E. F. Fluid and fuel intake during exercise. Journal of Sports Sciences. 2004; 22:39-55.

[5] Christophe Lalanne, R Companion to Montgomery's Design and Analysis of Experiments, 2005.
[6] Delahunty CM, Piggott JR. Current methods to evaluate contribution and interactions of components to flavour of solid foods using hard cheese as an example. International Journal of Food Science and Technology. 1995;30:555-570.

[7] Gillette M. Flavor effects of sodium chloride. Food Technology. 1985; 39(6):47-52.

[8] Hutton T. Sodium: Technological functions of salt in the manufacturing of food and drink products. British Food Journal. 2002;104(2):126-152.

[9] Harry T. Lawless \& Hildegarde . Sensory evaluation of food Principles and practices : Heymann International Thomson Publishing Services Ltd, Cheriton House, North Way, Andover SP10 5BE, U.K. 819 pp,1998.

[10] Leshem M. Biobehavior of the human love of salt. Neuroscience and Biobehavioral. Reviews. 2009;33(1):1-17.

[11] Manabe M, Ishizaki S, Yoshioka T, Oginome N. Improving the palatability of salt-reduced food using dried bonito stock. Journal of Food Science. 2009;74(7):S315-S321.

[12] Murakami, H.; Yoneyama, T.; Nakajima, K.; Kobayashi, M. Correlation between loose density and compactibility of granules prepared by various granulation methods. Int. J. Pharm. 2001; 216:159-164.

[13] MacGregor G, de Wardener HE. Salt, diet and health: Neptune's poisoned chalice: The origins of high blood pressure. Cambridge, UK: Cambridge University Press; 1998.

[14] Mukherjee, S.; Bhattacharya, S. Characterization of agglomeration process as a function of moisture content using a model food powder. J. Texture Stud. 2006; 37: 3548.

[15] Rolls ET, Critchley HD, Verhagen JV, Kadohisa M. The representation of information about taste and odor in the orbitofrontal cortex. Chemosensory Perception. 2010;3(1):16-33.

[16] Ram C. Shaking things up: Low-sodium dishes offer flavor without sacrifice. Plate. 2008:59-64.

[17] Sawka, M.N., Montain, S.J. Fluid and electrolyte supplementation for exercise heat stress. American Journal of Clinical Nutrition.2000; 72:S564-72.

[18] Schifferstein HNJ, Verlegh PWJ. The role of congruency and pleasantness in odor-induced taste enhancement. Acta Psychologica. 1996;94(1):87-105.

[19] Shittu, T. A.; Lawal, M. O. Factors affecting instant properties of powdered cocoa beverages. Food Chem. 2007; 100:91-98

[20] Takashi, S.; Seibi, P. A. Paste and gel properties of prime corn and wheat starches with and without nitric liquids. Cereal Chem. 1988; 65: 474-483. 